\title{
The Potential of Serum Proteomics for Detection of Cancer: Promise or Only Hope?
}

\author{
Karl E. Krueger \\ Cancer Biomarkers Research Group, National Cancer Institute, National Institutes of Health, Bethesda, MD, USA
}

Early studies profiling serum proteomics by mass spectrometry (MS) as a potential cancer diagnostic tool were initially received with considerable excitement [1-3]. Sensitivities and specificities exceeding $90 \%$ were reported and at first it appeared that MS of the serum proteome would yield amazing clinical utility for diagnosis of cancers normally detected too late for positive prognostic outcomes. But then as others tried to verify these findings reality set in. Confirmation by other laboratories failed and just as quickly as excitement over serum proteomics rose, the pendulum swung the other direction and much skepticism over this approach was spawned [4, 5]. In this issue of OnKOlOGIE, de Noo et al. report on a paradigm using MALDI-TOF-MS for serum proteomic profiling, with an accuracy of breast cancer detection exceeding 95\% [6]. The authors designed the study to avoid or minimize key issues that plagued earlier studies so it is fitting to revisit to this field in light of recent developments.

The chief culprits leading to the demise of serum proteomics by MS were founded on study design. Bias and chance (or overfitting) were considered as probable explanations leading to misinterpretation of data $[7,8]$. Bias is encountered from inherent properties of the samples studied. Many intrinsic specimen characteristics may have no relationship with the disease in question, but are introduced by any number of factors dependent on logistics of sample collection or selection of subjects included in the study. Strict adherence to standard operating protocols of specimen collection and appropriate matching of case vs. control subjects are essential to minimize such sources of bias. Collection of case and control specimens by the same site(s) is preferred as each collection site will unavoidably introduce its own bias into how samples are collected. Overfitting commonly results when a large number of variables or features, as is typically found in serum proteomic profiling, are used to differentiate from a limited number of states (i.e. case vs. control). Chance often comes into play when certain features of the test set simply segregate to either population in some manner independent of the disease in question. The probability for discovery of such misleading discriminators is fostered with an increasing number of features under observation. Performing the same test on another large set of independent samples verifies whether a panel of features is correlated with the disease as opposed to overfitting.

Beyond the obstacles that bias and overfitting pose to MS serum proteomic profiling, another major consideration is the limitation of this technology to effectively analyze highly complex protein mixtures. Detection of ionized molecules using time-of-flight platforms is inversely related to molecular size such that peptides and small proteins are more readily detected by MS. This places a significant limitation on MS proteomic profiling. Blood protein levels range from nearly millimolar down to femtomolar concentrations [5, 9]. Typical cancer biomarkers currently used are found in the pico- to subnanomolar range [5]. Although MS is highly sensitive, application for serum profiling has demonstrated the ability to identify proteins at low- to submicromolar concentrations. This suggests that most expected serum peptide biomarkers may still be 'hidden in the grass' when using MS profiling.

Another drawback to using MS profiling of the serum proteome is the difficulty of standardizing and calibrating instrumentation across multiple sites in order to directly compare findings from different laboratories. A concerted effort to address this problem was performed by 6 laboratories associated with the Early Detection Research Network where analysis on a common test set of sera from 14 prostate cancer subjects and 14 controls was carried out [10]. It was encouraging to find that most sites correctly classified the blinded samples correctly, suggesting it may be feasible to use MS profiling across multiple institutions. A follow-up study is expected to be published shortly validating whether this platform demon-

\begin{tabular}{|c|c|}
\hline KARGER & (C) 2006 S. Karger GmbH, Freiburg \\
\hline $\begin{array}{l}\text { Fax +49 } 7614520714 \\
\text { E-mail Information@Karger.de } \\
\text { www.karger.com }\end{array}$ & $\begin{array}{l}\text { Accessible online at: } \\
\text { www.karger.com/onk }\end{array}$ \\
\hline
\end{tabular}

Karl E. Krueger, Ph.D.

Program Director, Cancer Biomarkers Research Group

Division of Cancer Prevention, National Cancer Institute, National Institutes of Health

6130 Executive Blvd., Suite 3147, Bethesda, MD 20892-7362, USA

Tel. +1 301 594-1044, Fax -8990

E-mail kruegerk@mail.nih.gov 
strates sufficient cross-institutional performance in a larger set of clinical specimens.

Recently renewed attempts at exploiting serum proteomic profiling by MS for clinical testing of cancer have been pursued. Analysis of the serum peptidome purportedly derived from cancer specific proteases has been suggested to offer a new angle at identifying cancer biomarkers for clinical diagnosis $[11,12]$. Some support and enthusiasm has been voiced for this novel twist [13]. Furthermore, as reported in this issue [6], MALDI-TOF-MS was used to analyze sera from patients at different stages of preinvasive to metastatic breast cancer and compared with appropriately matched control sera. Control subjects were matched with cancer patients according to age. A single standardized serum collection protocol was adhered to for all samples collected from a single site. These carefully controlled prerequisites minimize many sources of bias. As few as 2 peaks resulting from the serum MS profiles were found to be highly predictive in distinguishing cases from controls. Even cases of early stage ductal carcinoma in situ (DCIS) were positively segregated from controls. Could these new developments indicate that the pendulum has begun to swing the other way in favor of serum proteomic MS profiling as a clinical diagnostic tool?

Unfortunately, these hopeful studies may still suffer from some basic flaws raised by critics of proteomic profiling. The studies looking at cancer-dependent generation of specific peptide families received criticism for using specimens that exhibit bias from using age-unmatched controls and overfitting likely accounting for the biomarker panels identified [14]. In the current study by de Noo et al., overfitting is still a concern as no data were presented to show that the 2 dis- criminatory peaks exhibit similar performance in an independent set of specimens. Validation with independent sera would provide a greater level of confidence in the findings of their discovery-driven study. It is also likely that these peaks are represented among the more abundant proteins within serum. Many investigators have already identified similar classifiers with good discrimination, however, the identities of these proteins were elucidated to be products of acute phase reactants rather than being a direct product of the tumor. The differential expression of these protein peaks merely reflects the host response to the cancer, a response that can be mimicked in other inflammatory reactions. To quiet the critics, additional control experiments are essential, such as using control subjects with other types of inflammatory disease, or even other cancers. Given the history of pitfalls encountered by so many labs, it is essential to perform rigorous studies using appropriate types of control specimens including multiple confounders to rule out general inflammatory or immune responses to another pathological condition. Without this level of care and detail in serum profiling, protein identification of any discriminatory peaks is critical.

In summary, the possibility of using proteomic profiling as a clinical test for cancer diagnosis is still being explored by devoted laboratories, despite many more scientists being skeptical that this approach will work. Only a rigorous and exhaustive experimental tact to effectively avoid all the pitfalls known to plague this approach will quiet the critics. With a guarded degree of anticipation, many still await the time when serum proteomic profiling will become more of a veritable promise than just a hope for the clinical community.

\section{References}

1 Adam BL, Qu Y, Davis JW, Ward MD, Clements MA, Cazares LH, Semmes OJ, Schellhammer PF, Yasui Y, Feng Z, Wright GL, Jr.: Serum protein fingerprinting coupled with a pattern-matching algorithm distinguishes prostate cancer from benign prostate hyperplasia and healthy men. Cancer Res 2002;62:3609-3614.

$>_{2}$ Petricoin EF, Ardekani AM, Hitt BA, Levine PJ, Fusaro VA, Steinberg SM, Mills GB, Simone C, Fishman DA, Kohn EC, Liotta LA: Use of proteomic patterns in serum to identify ovarian cancer. Lancet 2002;359:572-577.

3 Zhu W, Wang X, Ma Y, Rao M, Glimm J, Kovach JS: Detection of cancer-specific markers amid massive mass spectral data. Proc Natl Acad Sci U S A 2003;100:14666-14671.

4 Baggerly KA, Morris JS, Edmonson SR, Coombes KR: Signal in noise: evaluating reported reproducibility of serum proteomic tests for ovarian cancer. J Natl Cancer Inst 2005;97:307-309.

$\checkmark 5$ Diamandis EP: Analysis of serum proteomic patterns for early cancer diagnosis: drawing attention to potential problems. J Natl Cancer Inst 2004;96: 353-356.
6 de Noo ME, Deelder A, van der Werff M, Özalp A, Mertens B, Tollenaar R: MALDI-TOF serum protein profiling for the detection of breast cancer. Onkologie 2006;29: DOI: 10.1159/000095933.

7 Ransohoff DF: Lessons from controversy: ovarian cancer screening and serum proteomics. J Natl Cancer Inst 2005;97:315-319.

8 Ransohoff DF: Bias as a threat to the validity of cancer molecular-marker research. Nat Rev Cancer 2005;5:142-149.

9 Hortin GL, Jortani SA, Ritchie JC, Jr., Valdes R, Jr., Chan DW: Proteomics: a new diagnostic frontier. Clin Chem 2006;52:1218-1222.

10 Semmes OJ, Feng Z, Adam BL, Banez LL, Bigbee WL, Campos D, Cazares LH, Chan DW, Grizzle WE, Izbicka E, Kagan J, Malik G, McLerran D, Moul JW, Partin A, Prasanna P, Rosenzweig J, Sokoll LJ, Srivastava S, Srivastava S, Thompson I, Welsh MJ, White N, Winget M, Yasui Y, Zhang Z, Zhu L: Evaluation of serum protein profiling by surface-enhanced laser desorption/ionization timeof-flight mass spectrometry for the detection of prostate cancer: I. Assessment of platform reproducibility. Clin Chem 2005;51:102-112.
11 Villanueva J, Gonzalez A, Cornejo M, Nunez C, Encina S: Osteochondroma of the coronoid process. Med Oral Patol Oral Cir Bucal 2006;11: E289-291.

12 Villanueva J, Shaffer DR, Philip J, Chaparro CA, Erdjument-Bromage H, Olshen AB, Fleisher M, Lilja H, Brogi E, Boyd J, Sanchez-Carbayo M, Holland EC, Cordon-Cardo C, Scher HI, Tempst P Differential exoprotease activities confer tumorspecific serum peptidome patterns. J Clin Invest 2006;116:271-284.

13 Liotta LA, Petricoin EF: Serum peptidome for cancer detection: spinning biologic trash into diagnostic gold. J Clin Invest 2006;116:26-30.

14 Diamandis EP: Peptidomics for cancer diagnosis: present and future. J Proteome Res 2006;5: 2079-2082. 